


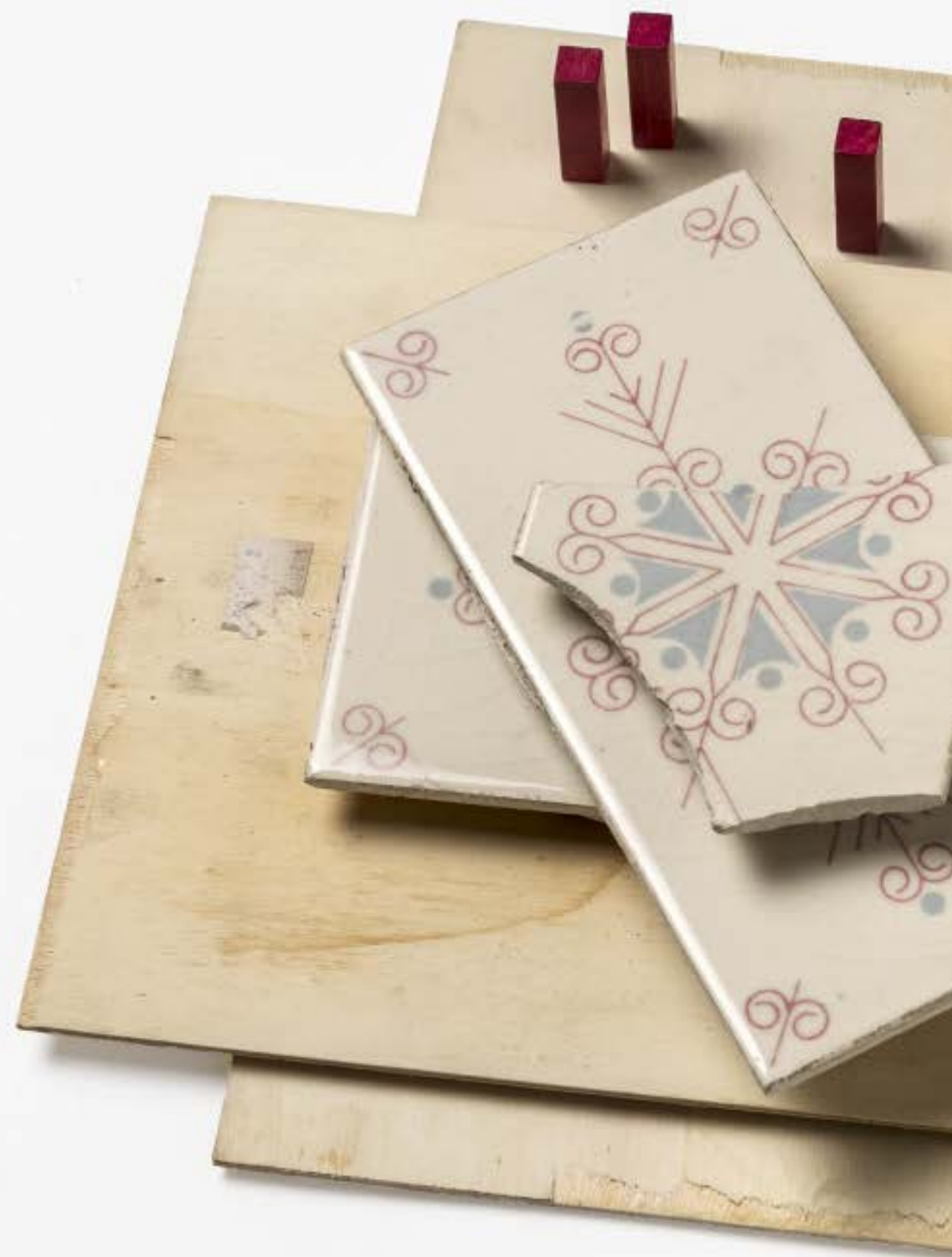




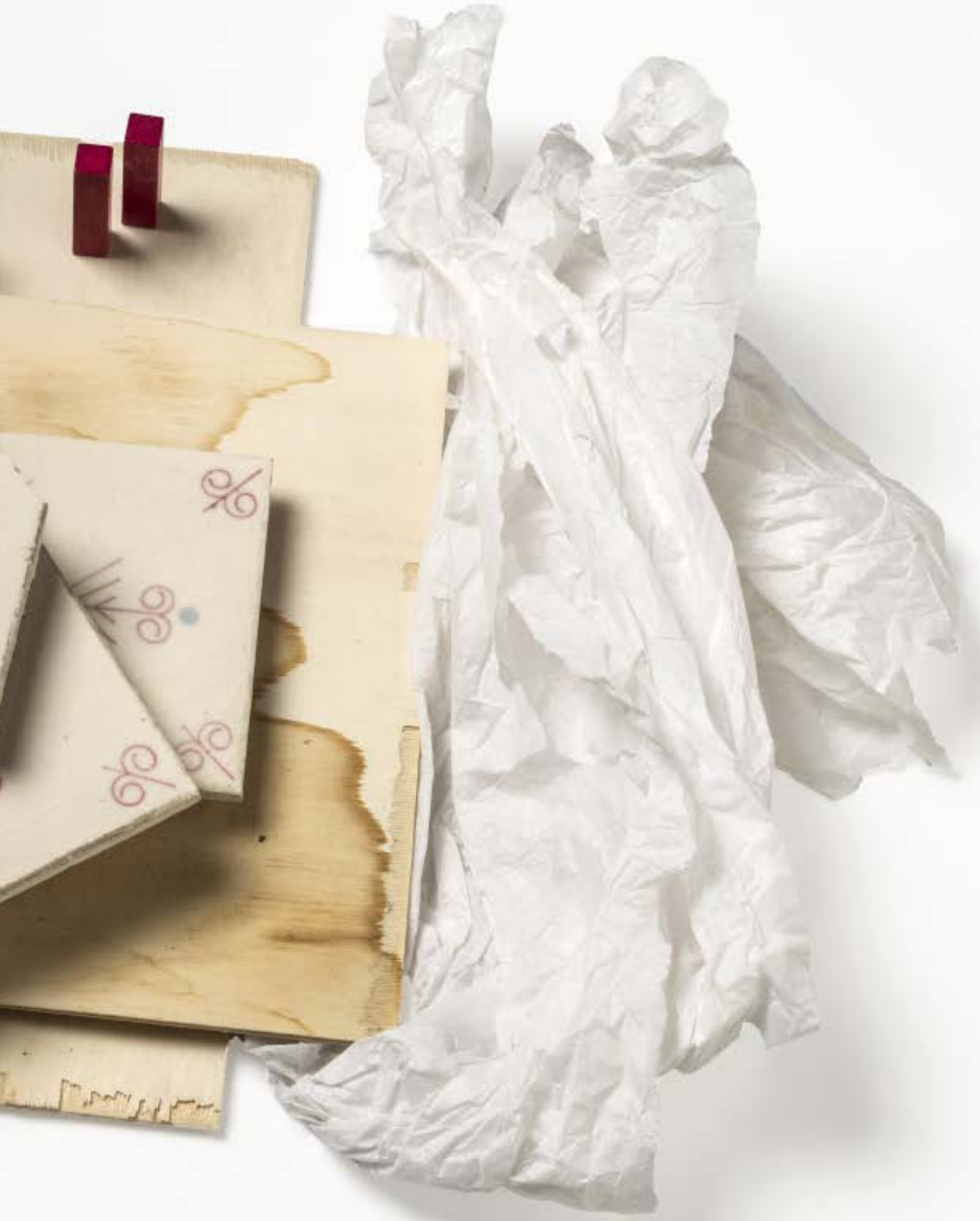



Izabrao sam dvije vrste istih za kupaonicu, svijetliju i tamniju nijansu.

I zamolio majstora da ih postavi tako da nema nikakvog pravila, šahovskog polja, dijagonala, križeva, ikseva i slično. Nazvao me oko dva i rekao da to nije moguće, štogod pokuša, kako god krenuo, uvijek ispada neko pravilo. 


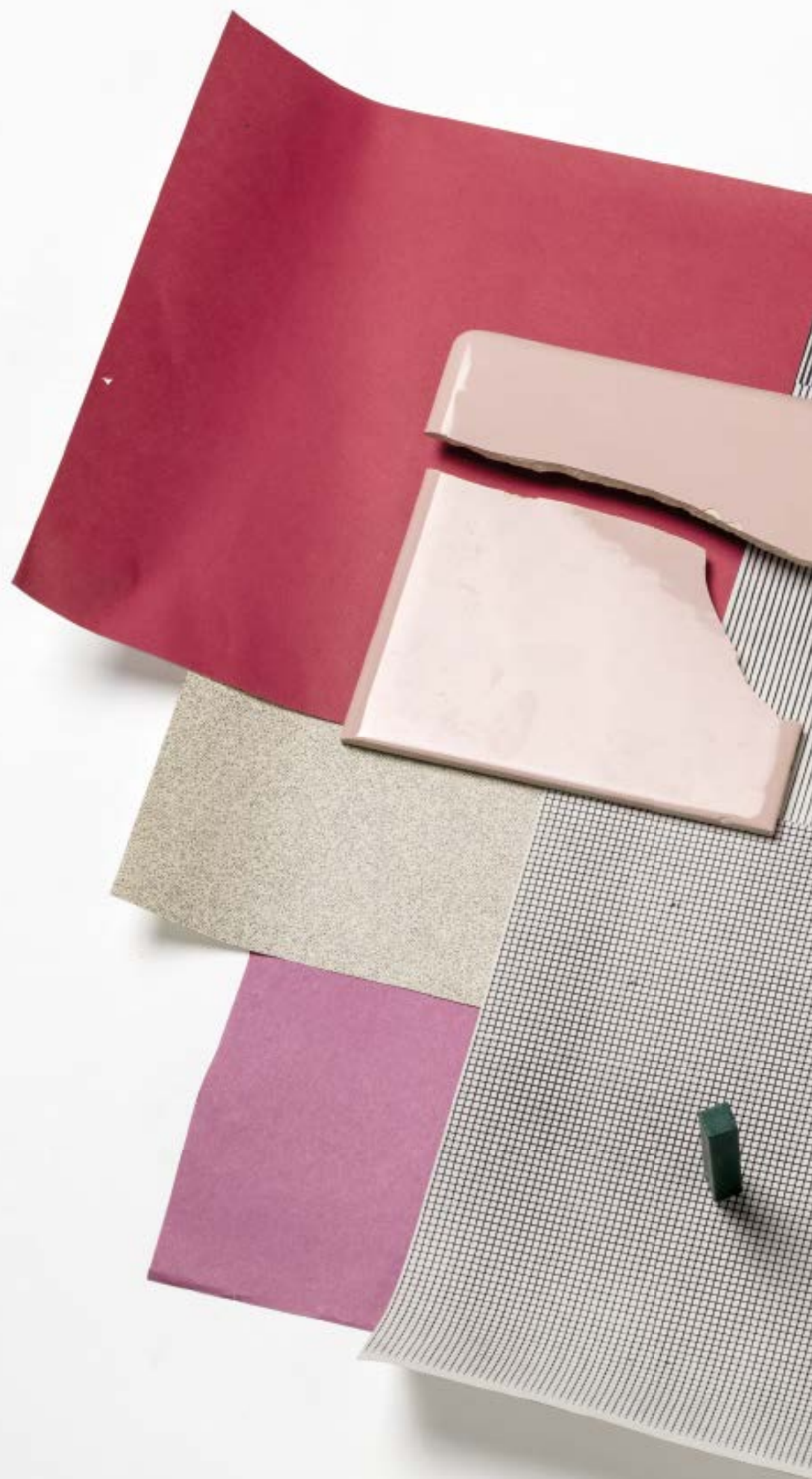




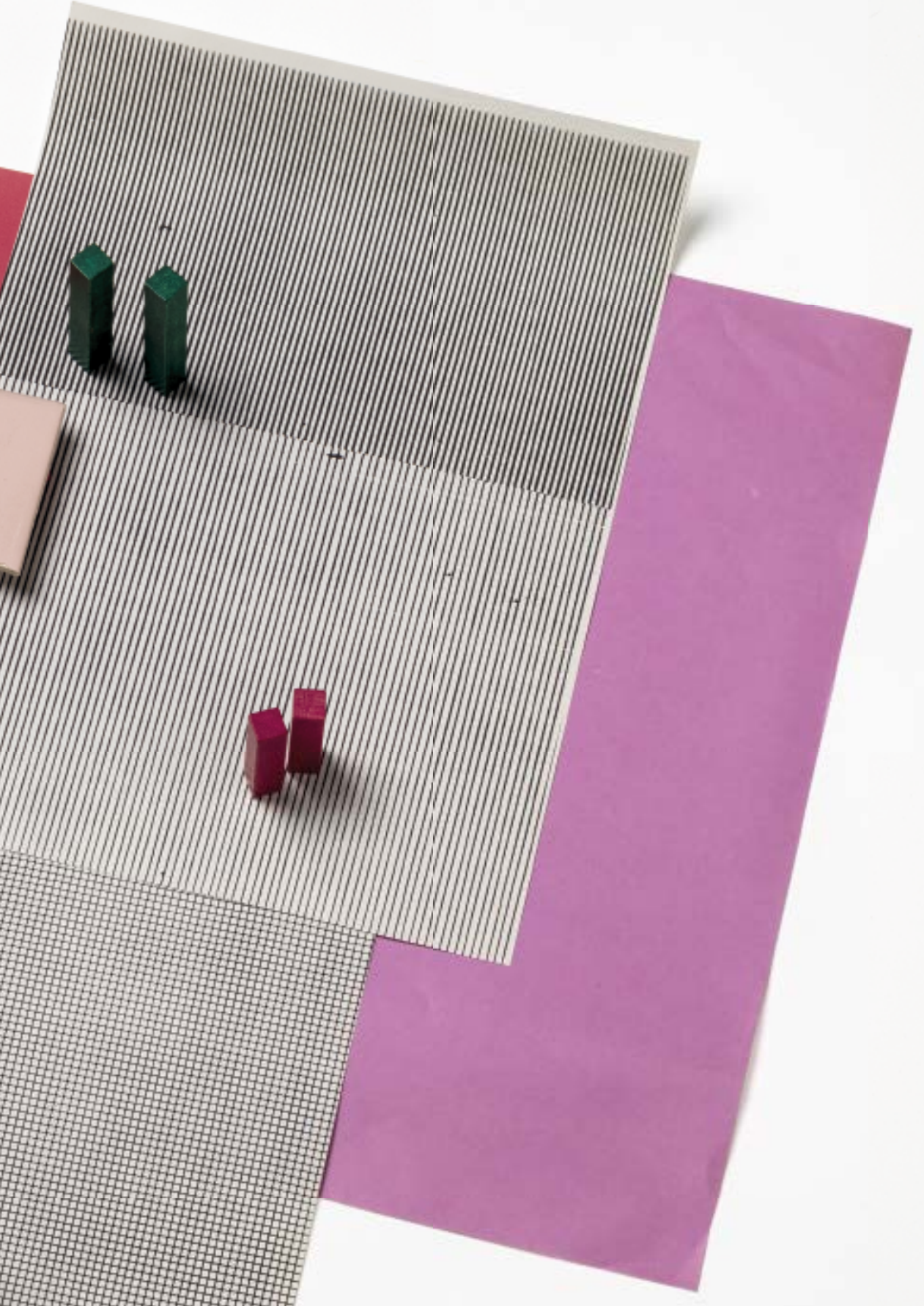



Neobično je bilo sjediti za njihovim kuhinjskim stolom, skoro pa malo i 'scary'. Mi sjedimo, a njegovi starci stoje i gledaju nas. Sve su servirali i sad se zadovoljno smješkaju, kao na djecjem rodendanu. Ali mi nismo djeca i on nema rodendan, nego je bio kod nas nekoliko puta na večeri, pa je valjda mislio da je na njega red. I sad mi jedemo, a oni nas gledaju. Prekrižene ruke, naslonjeni na zid, a na zidu neke africke pločice. Oni se smijulje, čekaju da se dobro najedemo pa da nas bace u lonac. 


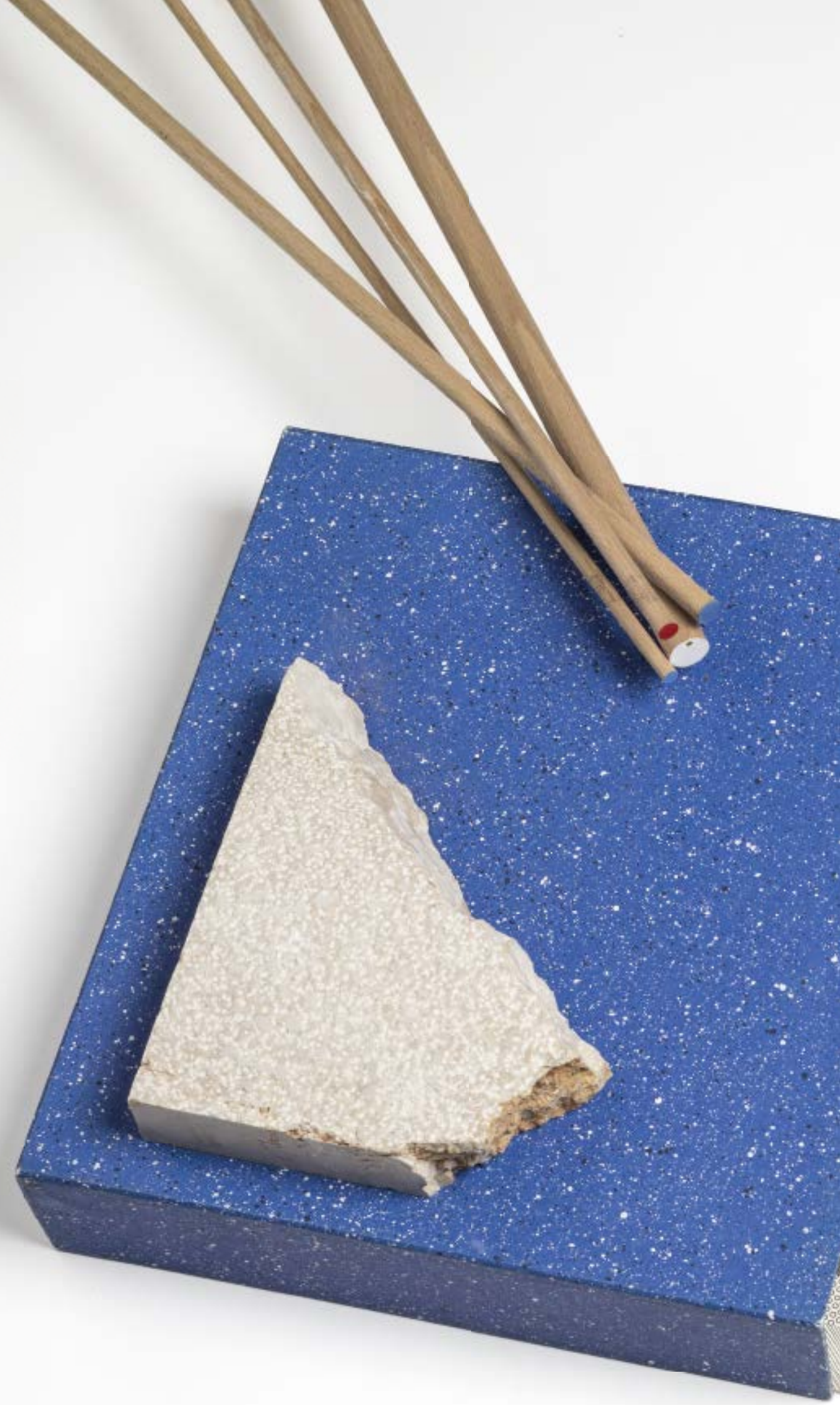




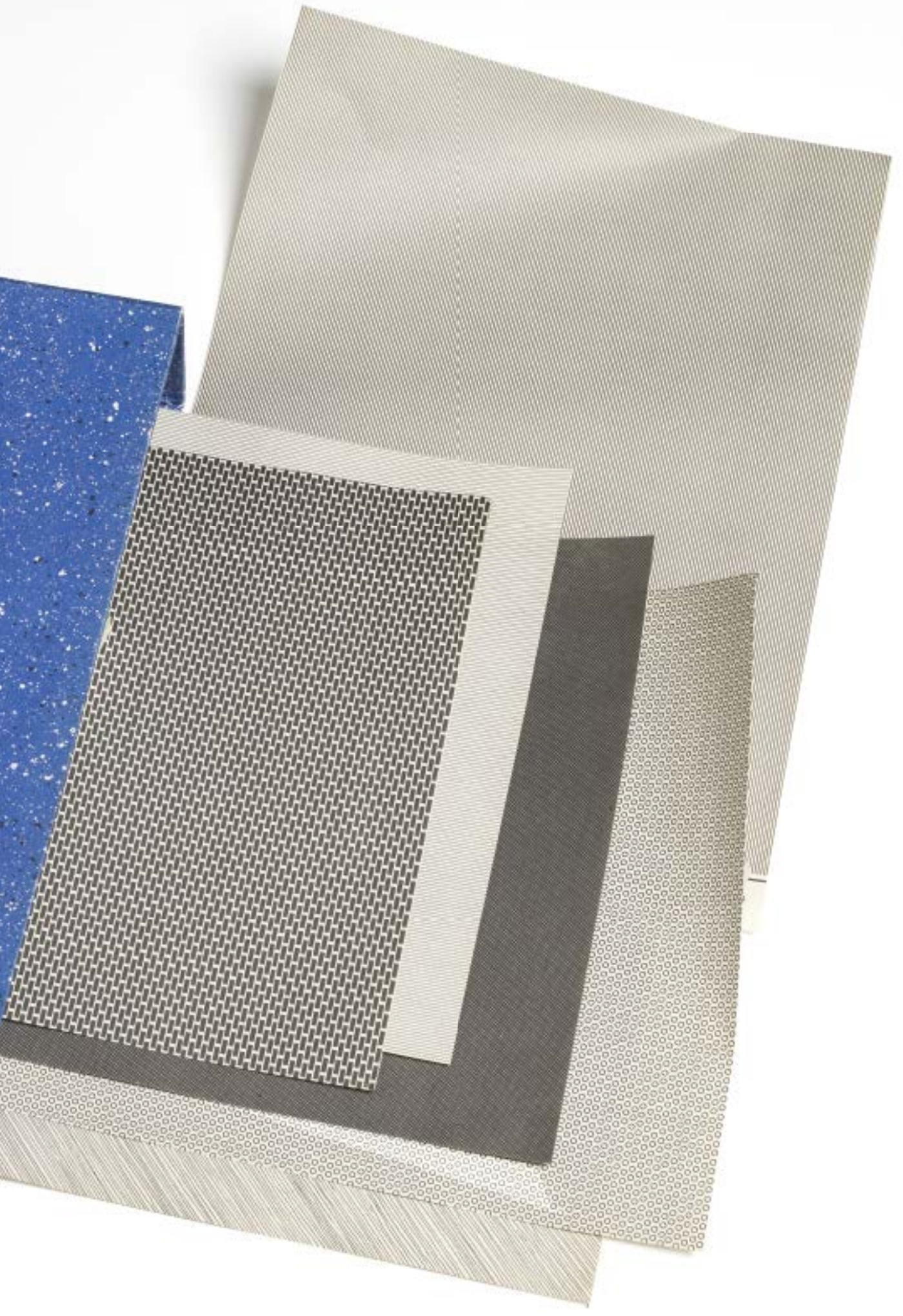



IKEA je odlučlla poslušati moj prijedlog i u ponudu uvela seriju pločica pod imenom „Gestalt“.

Uzeti su, naime, motivi i dizajni svih dosadašnjih serija i prilagodeni istom formatu. Prodaju se po kvadratu, s time da imaju sedamnaest razlicitih varijanti kvadrata sastavljenih od razlicitih motiva i dizajna i ne može se znati koje će se varijante dobiti. Kupci pristaju na koncept, a seriju od milja nazivaju 'pločice u vreći'. 


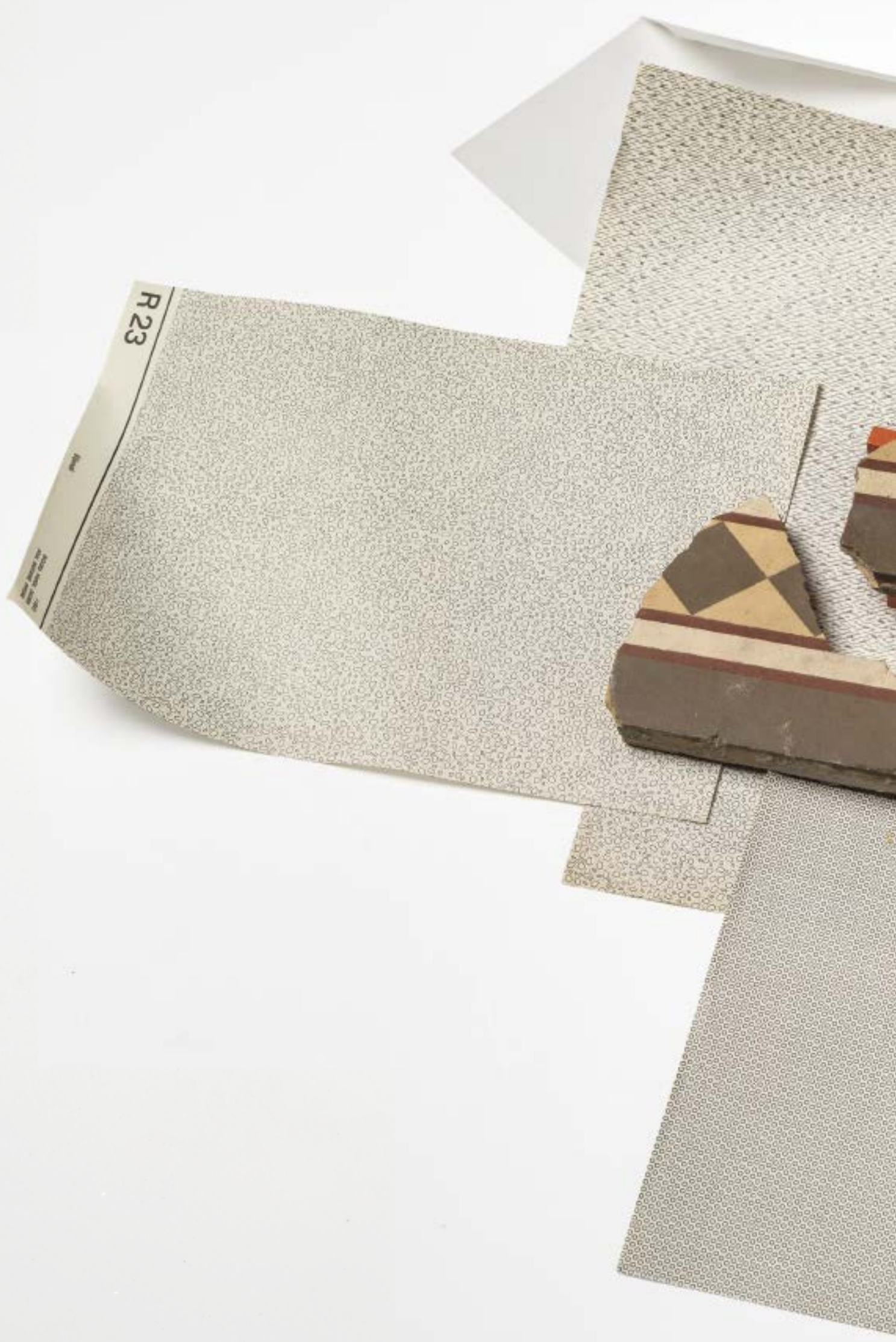




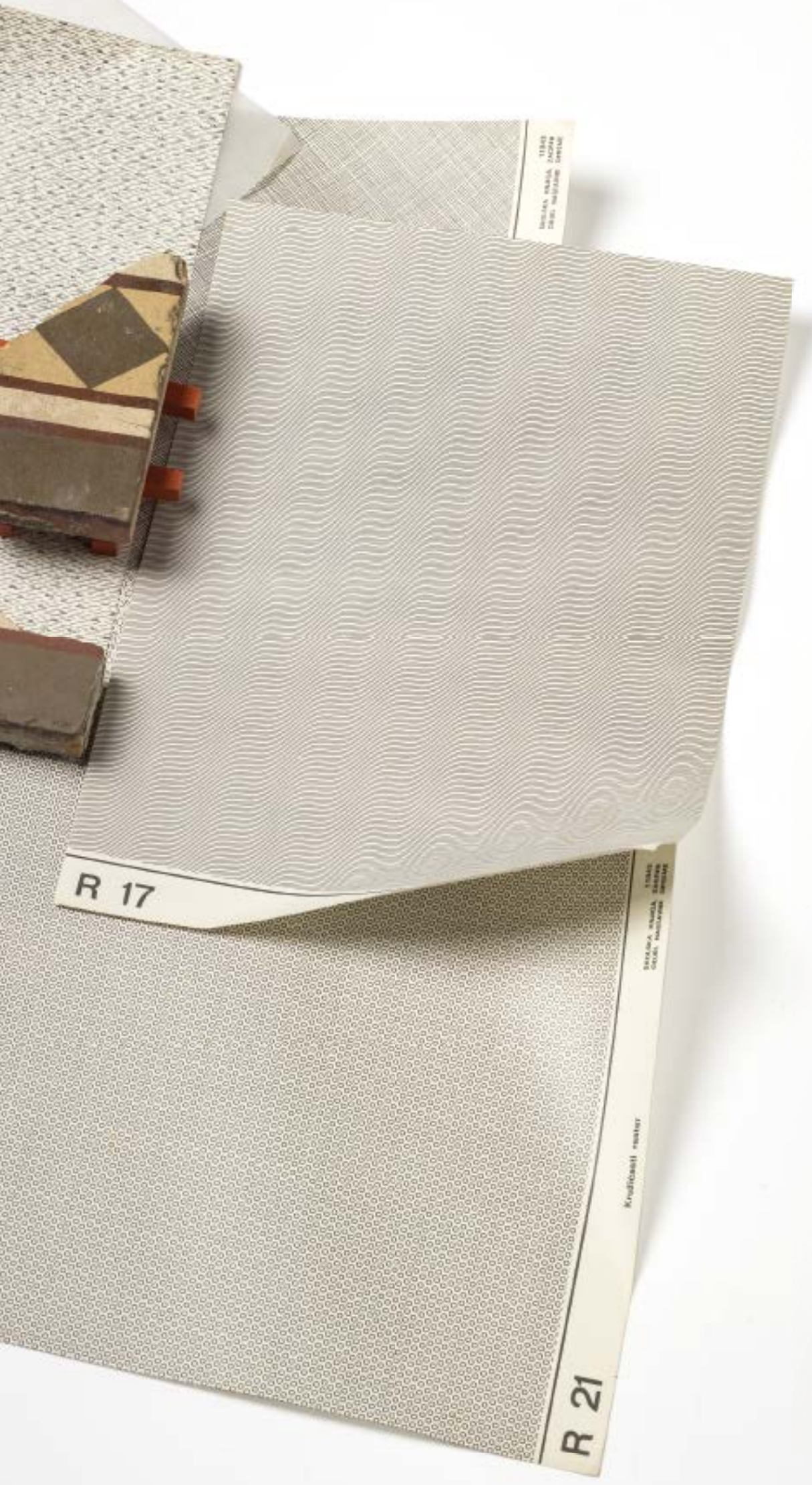


Maja Marković (Zagreb, 17. rujna 1979.) multimedijalna je umjetnica. Magistrirala je slikarstvo na Nastavničkom odsjeku Akademije likovnih umjetnosti u Zagrebu (2011., klasa prof. A. Rašića). Za svoj rad primila je više priznanja i nagrada. Boravila je na više internacionalnih rezidencijalnih programa. Kontinuirano izlaže u Hrvatskoj i inozemstvu od 2007. godine. Asistirala je na nekoliko filmskih i kazališnih projekata. Radila je kao vanjski predavač na Akademiji likovnih umjetnosti u Zagrebu. U svome umjetničkom radu istražuje koncepte prostora, interpretirajući prostor kroz crtež, fotografiju, prostornu instalaciju i zvuk. Članica je HDLU-a i HZSU-a. Živi i radi u Zagrebu.

\section{MAJA MARKOVIĆ}

Cvijete Zuzorić 23, 10000 Zagreb

mamarkovic@gmail.com

https://majamarkovic.org/

+ 385 (0)98522000
Maja Marković (Zagreb, September I7, I979) is a multimedia artist. She received her master's degree in painting from the Department of Art Education of the Academy of Fine Arts in Zagreb (20II, prof. Ante Rašić). She received several awards for her work. She took part in several international art residency programs. She has been continuously exhibiting in Croatia and abroad since 2007. She assisted in several film and theatre projects. She was engaged as a guest professor at the Academy of Fine Arts in Zagreb. In her artistic practice, she explores the concepts of space, interpreting the space through drawing, photography, installation and sound. She is a member of HDLU (Croatian Association of Artists) and HZSU (Croatian Freelance Artists' Association). She lives and works in Zagreb.

\section{MAJA MARKOVIĆ}

Cvijete Zuzorić 23, I000o Zagreb mamarkovic@gmail.com https://majamarkovic.org/

+385 (o) 98522000 $\leftarrow$

„FRAGMENTI PRIJELOMA”

Autori: IVANA BOROVNJAK, dizajn; BORIS CVJETANOVIĆ, fotografija; BORIS GREINER, tekst; MAJA MARKOVIĆ, scenografija prizora i izbor materijala (...) $\leftarrow$

\section{"FRAGMENTS OF THE LAYOUT"}

Autori: IVANA BOROVNJAK, design; BORIS CVJETANOVIĆ, photography; BORIS GREINER, text; MAJA MARKOVIĆ, scene scenography and selection of materials (...) 